\title{
Pollution and physiological variability in gentoo penguins at two rookeries with different levels of human visitation
}

\author{
ANDRÉS BARBOSA ${ }^{1,2}$, EVA DE MAS ${ }^{2}$, JESÚS BENZAL ${ }^{2}$, JULIA INES DIAZ ${ }^{3}$, MIGUEL MOTAS ${ }^{4}$, \\ SILVIA JEREZ ${ }^{4}$, LUIS PERTIERRA ${ }^{5}$, JAVIER BENAYAS ${ }^{5}$, ANA JUSTEL ${ }^{5}$, PILAR LAUZURICA ${ }^{6}$, \\ FRANCISCO JAVIER GARCIA-PEÑA ${ }^{7}$ and TANIA SERRANO ${ }^{7}$ \\ ${ }^{I}$ Departamento Ecología Evolutiva, Museo Nacional de Ciencias Naturales, CSIC, C/José Gutierrez Abascal, 2, 28006 Madrid, Spain \\ ${ }^{2}$ Departamento Ecología Funcional y Evolutiva, Estación Experimental de Zonas Áridas, CSIC, Carretera de Sacramento s/n, \\ La Cañada de San Urbano, 04120 Almeria, Spain \\ ${ }^{3}$ Centro de Estudios Parasitológicos y de Vectores, CONICET, Universidad Nacional de La Plata, Calle 2 584, CCT La Plata, \\ Buenos Aires, Argentina \\ ${ }^{4}$ Departamento Toxicología, Facultad de Veterinaria, Universidad de Murcia, Campus Espinardo, 30100 Murcia, Spain \\ ${ }^{5}$ Departamento Ecología, Universidad Autónoma de Madrid, 28049 Madrid, Spain \\ ${ }^{6}$ Unidad de Activación Inmunológica, Centro Nacional de Microbiología, Instituto de Salud Carlos III, Crtra Pozuelo Km 2 , \\ 28229 Majadahonda, Spain \\ ${ }^{7}$ Laboratorio Central de Veterinaria, Crtra Algete Km 8, 28110 Algete, Spain \\ barbosa@mncn.csic.es
}

\begin{abstract}
Human activity and specifically tourism has been increasing in Antarctica over the last few years. Few studies have examined the indirect effects of human visits on Antarctic penguin rookeries. This work aims to study the differences between a highly visited (Hannah Point) and a rarely visited (Devil's Point, Byers Peninsula) gentoo penguin rookery on Livingston Island. Our results suggest that potential indirect effects of human impact are observed in gentoo penguins at Hannah Point, a colony heavily visited by tourists. Penguins at Hannah Point showed a higher presence of heavy metals such as $\mathrm{Pb}$ and $\mathrm{Ni}$ and a higher number of erythrocytic nuclear abnormalities than penguins at Devil's Point. Immunological parameters showed different results depending on whether we consider the cellular response - the number of lymphocytes being higher in penguins from Hannah Point - or the humoral response - the level of immunoglobulins being higher in penguins from Devil's Point. Measurements of corticosterone levels in feathers and heterophil/lymphocyte $(\mathrm{H} / \mathrm{L})$ ratio in blood showed lower levels in the heavily visited rookery than in the rarely visited rookery. Finally, we did not detect Campylobacter jejuni, a bacteria potentially transmitted by humans in either of the populations and we did not find any difference in the prevalence of Campylobacter lari between the populations.
\end{abstract}

Received 29 November 2011, accepted 4 July 2012

Key words: Antarctic penguins, genotoxic damage, human disturbance, immune response, pollution, stress

\section{Introduction}

Human activity, and especially tourism, has been increasing in Antarctica in recent years. In the last ten years, the number of tourists visiting Antarctica has increased threefold, reaching a maximum during the 2007-08 summer season with around 42000 visitors (IAATO 2010). Therefore, concern about its impact on Antarctic ecosystems has increased in parallel (Tin et al. 2009). As penguins are one of the most popular tourist attractions, they are among the most likely to be affected by the impact of tourism. On the other hand, penguins are considered good models to use as sentinels of the marine environment, reflecting not only the probable direct effects of tourists visiting their colonies on shore, but also changes occurring in the surrounding waters. Human disturbance of penguins would probably cause behavioural and/or physiological changes due to increased stress, which could have negative consequences on their survival or reproduction (Walker et al. 2006). Human impact may be direct by pedestrian approach (Tin et al. 2009), or indirect through pollution (Metcheva et al. 2006), or by introducing diseases in either the penguins themselves or their surroundings (Curry et al. 2002). Most studies on Antarctic penguins have attempted to measure direct human impact (see the review by de Villiers 2008; but see Bonnendahl et al. 2005 for the only study dealing with human pathogens in penguins). Several studies have examined the effects of the approach of pedestrians on stress as measured by changes in heart beat (Nimon et al. 1995, Giese 1996, Holmes et al. 2005), while others have focused on changes in the number of penguins breeding or breeding success in visited areas compared to other places not visited (Giese 1996, Fraser \& Patterson 1997, Cobley \& Shears 1999, Otley 2005, Holmes et al. 2005, 


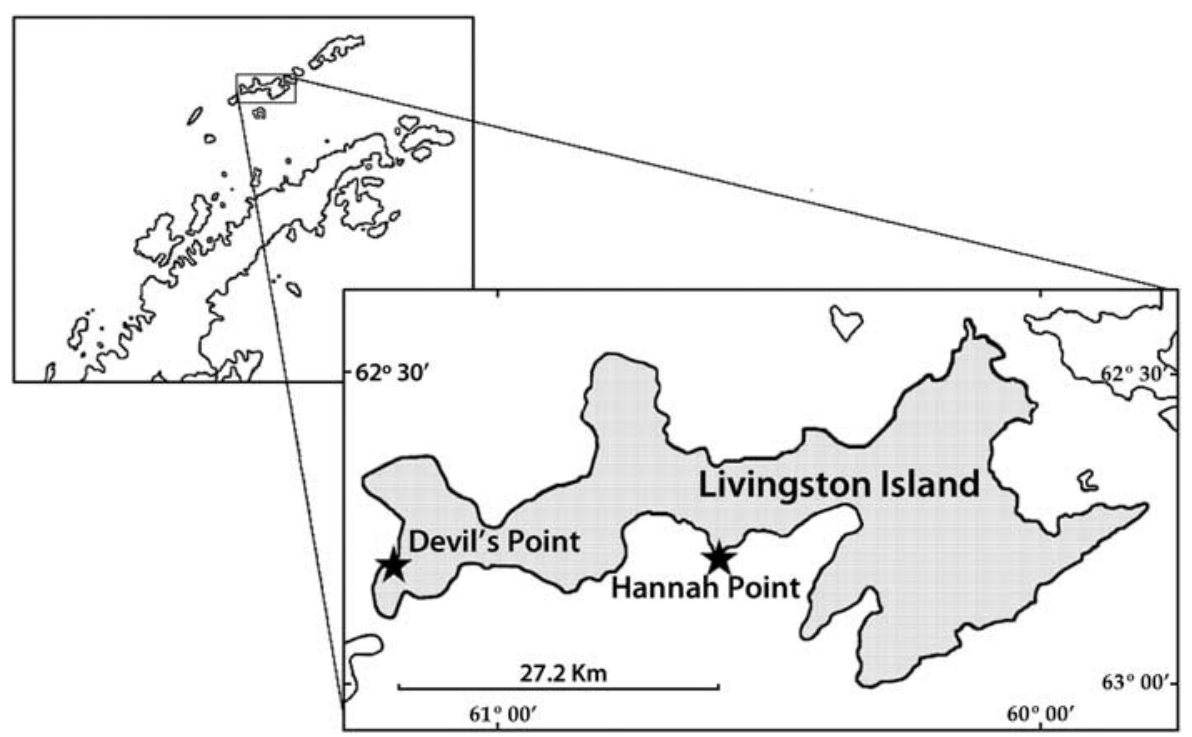

Fig. 1. Map of Livingston Island showing the location of the two penguin rookeries.
Carlini et al. 2007, Bricher et al. 2008, Trathan et al. 2008, Lynch et al. 2010). The results of these studies are not conclusive, as some have found minimal impact of human visits on penguins with no effect on their breeding success (Fraser \& Patterson 1997, Cobley \& Shears 1999, Otley 2005, Holmes et al. 2005, Carlini et al. 2007), while others have found negative effects (Giese 1996, Bricher et al. 2008, Trathan et al. 2008, Lynch et al. 2010).

However, few studies have been carried out on the indirect human impact on Antarctic penguin rookeries. In fact only one study, by Bonnendahl et al. (2005), investigated the presence in penguins of bacterial pathogens of potentially human origin such as Campylobacter jejuni, Salmonella spp. and Yersinia spp. Our work tries to fill this gap by studying such indirect effects as the presence of pollution, pathogens, and genotoxic and physiological effects, including the level of stress and immunological parameters in two different gentoo penguin (Pygoscelis papua Forster) rookeries, one heavily visited and one strictly protected in an Antarctic Specially Protected Area (ASPA). As gentoo penguins are especially sensitive to human disturbance (Holmes 2007), this species is very well suited for this approach.

The place selected for study as an example of a heavily visited penguin rookery is located at Hannah Point $\left(62^{\circ} 39^{\prime} \mathrm{S}, 60^{\circ} 36^{\prime} \mathrm{W}\right.$, Fig. 1), one of the most popular locations for observing penguins in Antarctica (7554 visitors in 2005-06 (IAATO 2010)) and so included in the Antarctic Treaty Secretariat list of visited sites with specific tourist guidelines (ATS www.ats.aq). Researchers also visit this place. We estimate a maximum of 30 researchers per year could be considered reasonable. As an example of a highly protected rookery, we chose the penguin rookery located at Devil's Point on Byers Peninsula $\left(62^{\circ} 40^{\prime} \mathrm{S}, 61^{\circ} 13^{\prime} \mathrm{W}\right.$, Fig. 1). Byers Peninsula is protected as ASPA number 126 under the Antarctic Treaty which means that only researchers with a permit issued by their national polar authority may enter this area. There is no record of research ever having been carried out in the Devil's Point rookery, and therefore it has seldom been visited. These two rookeries were chosen because they are near each other on Livingston Island so comparison between two places close together excludes any latitudinal effects (see Barbosa et al. 2007a, 2007b, 2011).

The aim of this study is to find out whether or not there are differences between these two areas in factors that could be indirectly derived from the presence of human activity:

1) Contaminants (heavy metals): penguins are biomonitors of marine contamination (Jerez et al. 2011) and therefore can be used for comparing the levels of contaminants in different places with different levels of human activity. Although heavy metals can have a natural origin, they are also originated from human sources such as fuel combustion, waste incineration, sewage disposal, paint etc (Bargagli 2008).

2) Erythrocytic nuclear abnormalities (ENAs) as a measure of genotoxic effects derived from pollution (Van Ngan et al. 2007). Most contaminants are known to be genotoxic and then can affect DNA causing genetic alterations leading to mutations. Differences in the level of contamination due to human activity can therefore be monitored through the level of ENAs presence in species such as penguins.

3) The presence of potential pathogenic bacteria such as Campylobacter spp., which can be derived from the presence of humans, e.g. Campylobacter jejuni (Bonnedahl et al. 2005) as an indicator that bacteria from human origin are present. 
4) Corticosterone level. Corticosterone (CORT) is the basic adrenal glucocorticod in penguins that allows fast adaptation on individuals to stressors through an increased energy supply (Holberton et al. 1996). Thus, it has been used to measure stress and fitness capacity in different situations including disturbance by human visitation (Walker et al. 2006, Villanueva et al. 2012). Heterophil/lymphocyte (H/L) ratio as an expression of stress (Maxwell \& Robertson 1998) has been shown as a physiological index of chronic stress in birds that may be useful in assessing response to chronic stressor (Gross \& Siegel 1983). Human disturbance is considered a main factor increasing chronic stress in animal populations.

5) Differences in immunological parameters, leukocyte profile and immunoglobulin level as an expression of the interaction between diseases, the immunosuppression effects of pollution (Snoeijs et al. 2004) and stress (Saino et al. 2003).

We expect pollution, erythrocytic nuclear abnormalities, and the presence of Campylobacter jejuni to be higher at Hannah Point, the more heavily visited colony, than at Devil's Point, the protected colony. Corticosterone response has been also measured to have an indication of human disturbance in penguins (Walker et al. 2006, Ellenberg et al. 2007, Villanueva et al. 2012) both for baseline and acute CORT levels in blood. Several studies have shown that measures of stress may be lower in animals regularly disturbed by tourists (Walker et al. 2006, Villanueva et al. 2012, but see Ellenberg et al. 2007) due to habituation. We therefore expect stress indicators to be lower at Hannah Point. Prediction of immunological parameters is complicated. Immune response can be affected by several different factors, such as disease, pollution or high stress hormone levels. The more visited rookery may be predicted to have a higher probability of diseases transmitted by humans (see above), and therefore, higher immunological parameters would be expected. However, on the other hand, if stress indicators are low in the more visited colony (see above), immunological parameters would be higher. Finally, if pollution is higher in the visited colony, a lower immune response would be expected.

\section{Materials and methods}

\section{General methods and sample collection}

In January 2009, we visited the gentoo penguin rookeries at Devil's Point on Byers Peninsula (62 $\left.42^{\circ} \mathrm{S}, 61^{\circ} 13^{\prime} \mathrm{W}\right)$ and Hannah Point $\left(62^{\circ} 39^{\prime} \mathrm{S}, 60^{\circ} 36^{\prime} \mathrm{W}\right)$ on Livingston Island, South Shetland Islands (Fig. 1). Adult penguins were chosen at random and captured on the beach (21 individuals at Devil's Point and 20 at Hannah Point) in order to minimize disturbance in the breeding colonies (see Barbosa et al. 2007a, 2007b). A blood sample was taken from a foot vein with a heparinized capillary tube immediately after capture and one drop was smeared on individually marked microscope slides, air-dried, fixed in absolute ethanol for $5 \mathrm{~min}$ and later stained with Giemsa $\mathrm{pH} 7.2$ for $30 \mathrm{~min}$. The remaining sample was later centrifuged at $12000 \mathrm{rpm}$ for $10 \mathrm{~min}$ (relative centrifugal force $=14811 \mathrm{~g}$ ) to separate plasma from red blood cells, with the plasma frozen for later analyses. Cloacal swabs were collected and preserved in Amies transport medium with charcoal. Several feathers were also collected from each individual and kept in polyethylene bags until analysis. In addition, bones from dead penguins found in the rookery were collected and kept in individual polyethylene bags until analyses.

\section{Specific methods}

Trace element analyses

Bone samples (Devil's Point, $n=13$; Hannah Point, $n=8$ ) were collected and placed in individual polyethylene bags. Samples were collected from carcasses of birds that had died recently and were scavenged by skuas. The bones analysed were as follows: seven pelvis, two femur, three tibiotarsus and one humerus bones from Devil's Point and four pelvis, two femur and two humerus bones from Hannah Point). The analytical method was a modification of the one described in Jerez et al. (2010). Bone samples were rinsed in deionised water and cleaned in an ultrasonic bath to eliminate any external contamination, and dried at $75-80^{\circ} \mathrm{C}$ to constant weight. A section of the central part of the bone of about $1.5 \mathrm{~cm}$ was cut and after elimination of the soft internal tissue was crushed until a homogeneous powder was obtained. Then, around $0.4 \mathrm{~g}$ of the material, depending on availability, was subjected to microwave digestion with $\mathrm{HNO}_{3}(65 \%), \mathrm{H}_{2} \mathrm{O}_{2}(30 \%)$ and $\mathrm{H}_{2} \mathrm{O}$. $\mathrm{Al}, \mathrm{Cr}$, $\mathrm{Mn}, \mathrm{Fe}, \mathrm{Ni}, \mathrm{Cu}, \mathrm{Zn}, \mathrm{As}, \mathrm{Se}, \mathrm{Cd}$ and $\mathrm{Pb}$ were determined by mass spectrometry with inductively coupled plasma (ICP-MS Thermo-Optek Serio X7). All reagents used were Suprapur (Merck) and the water was double-distilled and deionised (Milli-Q system, Millipore, USA). Analytical precision was verified by using blanks every five samples, initial calibration standards and certified reference materials. Expressed in $\mathrm{ng} \mathrm{g}^{-1}$, the detection limit of each element was 3.88 for $\mathrm{Al}, 0.2$ for $\mathrm{Cr}$ and $\mathrm{As}, 0.4$ for $\mathrm{Mn}$ and $\mathrm{Ni}, 1.7$ for $\mathrm{Fe}, 0.8$ for $\mathrm{Cu}$ and $\mathrm{Pb}, 2.7$ for $\mathrm{Zn}, 0.7$ for $\mathrm{Se}$ and 0.1 for $\mathrm{Cd}$. The validity of penguin bones for measuring heavy metals has been pointed out by Honda et al. (1986).

Erythrocytic nuclear abnormalities

The frequency of ENAs was scored in each blood sample in relation with 10000 mature erythrocytes (Schmid 1975). Nuclear abnormalities were recorded following Van Ngan et al. (2007) and Kursa \& Bezrukov (2008). The sum of ENA was used in the statistical analysis. 


\section{Campylobacter spp. analyses}

One swab was taken from each individual and placed in FBP medium (Gorman \& Adley 2004) with $0.5 \%$ active charcoal. Samples were frozen at $-20^{\circ} \mathrm{C}$ until analysis. Each swab was placed in $10 \mathrm{ml}$ of Campylobacter enrichment broth (Lab M) with 5\% laked horse blood and CAT supplement (cefoperazone $\left(8 \mu \mathrm{g} \mathrm{ml}^{-1}\right)$, amphotericine B $\left(10 \mu \mathrm{g} \mathrm{ml}^{-1}\right)$ and teicoplanin $\left(4 \mu \mathrm{g} \mathrm{ml}^{-1}\right)$ at $37^{\circ} \mathrm{C}$. The broth was incubated at $37^{\circ} \mathrm{C}$ for $48 \mathrm{~h}$ and five days in 3.5-1 anaerobic containers using CampyGen sachets (Oxoid), before plating a $100 \mu \mathrm{l}$ aliquot on CAT agar and incubating at $37^{\circ} \mathrm{C}$ for 72 hours in a microaerobic atmosphere. In addition, a $47 \mathrm{~mm}$ diameter cellulose membrane with $0.6 \mu \mathrm{m}$ pore was placed on the surface of an Anaerobe Agar Base (Oxoid) with 5\% laked horse blood. Eight to ten drops of enrichment broth $(200 \mu l)$ were placed on the membrane surface. The membrane was left $20-30 \mathrm{~min}$ on the agar surface at room temperature until all the fluid had passed through (Steele \& MacDermott 1984). The plates were incubated as described above, but for five days to isolate the less common, slower growing species.

Isolates were examined by dark-field microscopy to determine morphology and motility and tested to determine whether oxidase was produced. Original Campylobacter spp. identification was done by Gram staining, catalase activity, hippurate hydrolysis, ability to hydrolyze indoxyl acetate, urease activity, $\mathrm{H}_{2} \mathrm{~S}$ production on triple sugar iron slants, growth at $25^{\circ} \mathrm{C}$ and $42^{\circ} \mathrm{C}$ in microaerophilic environment, growth at $37^{\circ} \mathrm{C}$ in aerobic atmosphere and agglutination with Microscreen latex (Microgen, Camberley, UK). No differences between strains were observed in any of the phenotypic tests used. All isolates showed a gram-negative, slender, curved, seagull wing-like morphology under light microscopy and positive reactions in the catalase test. They were negative to hippurate and indoxyl acetate hydrolysis and urease, and did not show $\mathrm{H}_{2} \mathrm{~S}$ production. In addition, they grew at $42^{\circ} \mathrm{C}$ but did not grow at $25^{\circ} \mathrm{C}$ or $37^{\circ} \mathrm{C}$ in aerobic atmosphere. Finally, all of them were positive in the agglutination test.

\section{Stress analyses}

Corticosterone levels

Fourteen feathers of similar length $(40 \mathrm{~mm})$ from each individual were analysed for each colony. The proximal part was removed, keeping the part containing most of the vane and barbs. The processed feathers weighed approximately $30 \mathrm{mg}$, which had previously been determined in a pilot study as sufficient for proper detection. Methanol-based extraction of corticosterone followed Bortolloti et al. (2008). Feathers were submerged in tubes with $15 \mathrm{ml}$ methanol. The samples were exposed for 30 minutes in a sonicating water bath at room temperature, followed by incubation for 24 hours at $50^{\circ} \mathrm{C}$ in a shaking water bath. The methanol fraction was filtered to separate it from the solid residual. Methanol was then evaporated in a water bath at $50^{\circ} \mathrm{C}$ in an extractor hood, which took 24 hours. After that, the remaining pellet was re-suspended in $500 \mu \mathrm{PBS}$ and stored frozen at $-20^{\circ} \mathrm{C}$ until corticosterone analysis. The amount of corticosterone in each sample was analysed in duplicate in a corticosterone ELISA of competition. Detection limits ranged from 37-75 to 5000-20000 pg. in commercial kits (Assay \& Arbor Designs). All samples were within these limits. Kits were validated and several controls were conducted prior to the study at several sample sizes $(100,50,30 \mathrm{mg})$ and dilutions $(1,1 / 2,1 / 4)$. Calibration curves were built for each reading based on known quantities from commercial CORT. Data were analysed per duplicate with maximum $15 \%$ variation between duplicates. Seven dilutions were made for calibration curves with values fitted to $98 \%$ or superior accuracy. Samples were measured in two plates with roughly half of the samples of each colony in each plate. Results followed similar trend in both kits, however the effect of the kit was considered in the statistical analyses (see Results).

\section{Heterophil/Lymphocyte ratio}

Heterophil and lymphocytes were counted in a total of 100 leukocytes in blood smears under 1000x oil immersion (Dufva \& Allander 1995) by the same person (ED). Leukocytes were counted in a part of the smear where cells had separated in a monolayer crossing the sample from bottom to top to minimize differences in the thickness of the blood smear (see Moreno et al. 1998 for method reliability).

\section{Immunological analyses}

Leukocyte profiles

All smears were examined by the same person (ED) under a 1000x oil immersion objective, and the proportions of different types of leukocytes following Hawkey \& Dennet (1989) were found by examining a total of 100 leukocytes (Dufva \& Allander 1995). The total leukocyte count per hundred fields was taken as a relative total white blood cell count (see Janes et al. 1994 for a similar method). Leukocytes were counted in a part of the smear where cells had separated in a monolayer crossing the sample from bottom to top to minimize differences in the thickness of the blood smear (see Moreno et al. 1998 for method reliability).

Immunoglobulin levels (IgY)

To measure total circulating IgG, the plasma fraction was analysed by means of direct ELISA using peroxidaseconjugated anti-chicken IgY antibodies (Sigma A-9046) used as reported by Martínez et al. (2003). The linear range of the sigmoidal curve for this antibody-antigen response, as well as the optimal serum dilution (1/12000), had been previously determined. Immunoglobulin levels were 
Table I. Metal and trace element concentrations (ppm dry weight) in bones from penguins of Byers Peninsula and Hannah Point. Data shown mean \pm standard error. * Denotes significant differences

\begin{tabular}{lcc}
\hline & Byers $(n=13)$ & Hannah Point $(n=8)$ \\
\hline $\mathrm{Al}$ & $32.28 \pm 14.96$ & $18.63 \pm 4.44$ \\
$\mathrm{Fe}$ & $114.99 \pm 30.61$ & $73.23 \pm 8.02$ \\
$\mathrm{Cr}$ & $0.08 \pm 0.02$ & $0.29 \pm 0.18$ \\
$\mathrm{Mn}$ & $18.35 \pm 2.28$ & $9.81 \pm 1.21$ \\
$\mathrm{Ni}$ & $0.61 \pm 0.05$ & $0.92 \pm 0.11^{*}$ \\
$\mathrm{Cu}$ & $1.15 \pm 0.33$ & $0.74 \pm 0.09$ \\
$\mathrm{Zn}$ & $244.62 \pm 7.99$ & $223.82 \pm 21.91$ \\
$\mathrm{As}$ & $0.19 \pm 0.04$ & $0.12 \pm 0.01$ \\
$\mathrm{Se}$ & $0.99 \pm 0.07$ & $1.17 \pm 0.13$ \\
$\mathrm{Cd}$ & $0.008 \pm 0.003$ & $0.005 \pm 0.001$ \\
$\mathrm{~Pb}$ & $0.0004 \pm 0.0004$ & $0.02 \pm 0.01^{*}$ \\
\hline
\end{tabular}

measured using a plate spectrophotometer at $\lambda=405 \mathrm{~nm}$ and expressed in units of absorbance (see Barbosa et al. 2007a for a similar approach).

Statistical analyses included one-way ANOVA, Chi-square and regression. All variables were checked for normality and appropriate transformations were used when necessary.

\section{Results}

\section{Trace elements}

Our results showed significant differences in the concentration of $\mathrm{Pb}$ and $\mathrm{Ni}$ in the bones of the penguins from the two locations. Penguin bones sampled at Hannah Point had higher concentrations of $\mathrm{Pb}$ and $\mathrm{Ni}$ than those sampled at Devil's Point $\left(F_{1,19}=5.08, P=0.03\right.$ and $\left.F_{1,19}=7.54, P=0.01\right)$. No differences were found in the remaining elements studied $(P>0.05$, Table I).

\section{Erythrocytic nuclear abnormalities}

Results showed that erythrocytic nuclear abnormalities were more frequent at Hannah Point than at Devil's Point rookery $\left(F_{1,18}=4.30, P=0.05\right.$; Hannah Point, mean $=19.10 \pm 4.70$; Devil's Point, mean $=5.30 \pm 4.70$ ).

\section{Campylobacter spp. analyses}

In all samples, the Campylobacter species isolated was Campylobacter lari. Campylobacter jejuni was not found in any of our samples, and no differences were found in the prevalence of Campylobacter lari between the two sites (chi-square $=0.36, P=0.54, \mathrm{df}=1$; Hannah Point, prevalence $=5 \%(1 / 20)$; Devil's Point, prevalence $=4.16 \%$ $(1 / 24))$.

\section{Stress analyses}

We found differences in the corticosterone levels in the feathers of penguins from the two populations. Corticosterone levels were higher in feathers belonging to the penguins in the Devil's Point rookery $(1.46 \pm 0.46)$ than in the Hannah Point population $(0.93 \pm 0.16)$ $\left(F_{1,30}=5.33, \quad P=0.02\right)$. We also found significant differences between both kits $\left(F_{1,30}=8.90, P=0.005\right)$, however the interaction between the locality and the kit was non significant $\left(F_{1,30}=0.20, P=0.65\right)$.

Our results showed that the heterophil/lymphocyte ratio was higher in penguins from the Devil's Point rookery (mean $=0.94 \pm 0.07$ ) than in penguins from Hannah Point $(0.75 \pm 0.07)$, although significance was only marginal $\left(F_{1,38}=3.17, P=0.08\right)$.

\section{Immunological analyses}

There were significant differences in the level of immunoglobulins between penguins at Devil's Point and at Hannah Point $\left(\mathrm{F}_{1,39}=9.13, P=0.004\right)$. Penguins from Devil's Point showed higher levels of immunoglobulins (mean $=0.76 \pm 0.03$ ) than the penguins from the Hannah Point population $(0.61 \pm 0.03)$.

We did not find significant differences between the two populations in basophils, monocites, eosinophils and heterophils $(P>0.05)$. However, we did find significant differences in the number of lymphocytes $\left(F_{1,39}=4.76\right.$, $P=0.03$ ), which were higher in the Hannah Point population than at Devil's Point $(44.31 \pm 3.03$ and $35.27 \pm 2.81$ respectively).

We did not find any relationship either in corticosterone levels in the feathers and immunoglobulins (Hannah Point: $r=0.23, P=0.37, n=16$, Devil's Point: $r=-0.05, P=0.86$, $n=14$ ) or between corticosterone levels in feathers and heterophil/lymphocyte ratios (Hannah Point: $r=0.29$, $P=0.26, n=16$, Devil's Point: $r=0.29, P=0.26, n=16$ ).

\section{Discussion}

As far as we know, this is the first time that a study has addressed the indirect effects of human impact in Antarctic penguins in a wide range of factors from pollution to immunology. Up to now, the studies carried out in Antarctic penguins have focused on direct effects on population size and breeding success (Giese 1996, Fraser \& Patterson 1997, Cobley \& Shears 1999, Otley 2005, Holmes et al. 2005, Carlini et al. 2007, Bricher et al. 2008, Trathan et al. 2008, Lynch et al. 2010). However, the results of those studies are far from providing a robust conclusion as to whether or not human visits have an effect on Antarctic penguins, as some found no effects while others did. These differences in results may be because some of the studies that found no effects on changes in population size or breeding success were carried out in just one breeding season (e.g. Cobley \& Shears 1999), while those finding negative effects were longterm studies (e.g. Trathan et al. 2008). Such differences may also be due to the variables measured or methods used (see Lynch et al. 2010). As the effects seem to be species-specific 
(Holmes 2007), results from different species could also arrive at different conclusions (see Lynch et al. 2010) explaining the inconsistencies found. Indirect effects, such as those we analyse here, could explain long-term changes.

\section{Trace elements}

We found higher levels of $\mathrm{Pb}$ and $\mathrm{Ni}$ in penguin bones from Hannah Point. $\mathrm{Pb}$ is a non-essential element (Smichowski et al. 2006), is not metabolically regulated (Gochfeld et al. 1996), and is one of the most suitable metals for monitoring anthropogenic pollution (Metcheva et al. 2006). $\mathrm{Pb}$ may come from fuel combustion, waste incineration, sewage disposal, paint or accidental oil spills (Bargagli 2008) and has been found in Antarctic penguin tissues such as feathers (Metcheva et al. 2006, Jerez et al. 2011). Ni is an essential metal from natural sources and is widely distributed in the environment (Eisler 1998). However, it can also originate in human activity such as mining, the chemical industry, fuel combustion, waste incineration, sewage disposal, paint or accidental oil spills (ATSDR 2005). Pb levels found in penguin feathers from Hannah Point were lower than other more polluted sites such as King George Island or Paradise Bay (Jerez et al. 2011). Moreover, Jerez et al. (2011) showed no differences in $\mathrm{Ni}$ concentration in penguin feathers from Hannah Point and other more polluted areas, such as King George Island or Paradise Bay. Unfortunately, we were unable to analyse the presence of heavy metals in feathers of penguins from Devil's Point, and so any differences in their levels remain to be tested. As far as we know, no data on the concentration of $\mathrm{Pb}$ or $\mathrm{Ni}$ in bones from gentoo penguins have been published, and therefore, it is impossible to find out whether the $\mathrm{Pb}$ level at Hannah Point is higher or lower than at other places in Antarctica. Although there is published data on heavy metal concentration in bones of Adélie penguins (Honda et al. 1986), interspecific differences in the concentration of heavy metals in different penguin species (Jerez et al. 2011) preclude a direct comparison of the pollution level in both studies. Contaminants present in bones are accumulated throughout the lifetime of the individual, while their presence in feathers expresses birds' exposure to them during moulting, and so our results in bones may be considered an indicator of long-term exposure. $\mathrm{Pb}$ in bird bones is considered to reach toxic levels when it exceeds $10 \mathrm{ppm}$ (Scheuhammer 1987). Our results show levels far below $10 \mathrm{ppm}$ which suggests that the biological effect should be very small. Nevertheless, our results are useful in that they show that a clear difference exists in the $\mathrm{Pb}$ levels in penguins from a highly protected colony with almost no contact with human activity and penguins from a site with a certain level of regular visitation, such as Hannah Point.

We did not find significant differences for the remaining elements analysed (Al, Fe, Cr, Mn, Cu, Zn, As, Se and Cd).
The lack of significant differences could be due to the lack of differences in the natural sources of some of these elements probably due to the proximity of the two sites but this is also possible because of the lack of differences in the composition of the remains due to human activity.

\section{Erythrocytic nuclear abnormalities}

Our results on genotoxic effects, measured as the number of ENAs, were higher at Hannah Point than in Devil's Point penguin populations. The erythrocytic abnormality count is one of the main methods for detecting genomic damage related to environmental deterioration and pollution (Van Ngan et al. 2007). Several different studies have shown the presence of contaminants as an inductor of ENAs (e.g. Stoncius \& Lazutka 2003). Afanasieva et al. (2006) studied erythrocytic abnormalities present in the population of gentoo penguins on Peterman Island $\left(65^{\circ} 10^{\prime} \mathrm{S}, 64^{\circ} 10^{\prime} \mathrm{W}\right)$, one of the most heavily visited localities in the Antarctic Peninsula (see Lynch et al. 2010). They found 20.0 abnormalities per 10000 erythrocytes (Afanasieva et al. 2006) which is very similar to what we found at Hannah Point and higher than recorded for the Devil's Point gentoo penguin population. It is also similar to erythrocytic abnormality records for gentoo penguin populations from other highly polluted locations (e.g. King George Island) (De Mas et al. unpublished). In an experiment on the Antarctic fish Trematomus newnesi Boulenger, Van Ngan et al. (2007) found that individuals in tanks filled with seawater taken from the fuel tank of the Brazilian Antarctic Research Station Comandante Ferraz, and in tanks filled with seawater taken from the sewage discharge outlet, had higher erythrocytic abnormalities than individuals in tanks filled with seawater taken far away from this research station. Such results confirm ours and show that the presence of contaminants in the environment causes a higher number of erythrocytic abnormalities. The biological significance for the penguins of these results is difficult to assess. Genomic instability has been linked with diseases (i.e. infertility, embryonic growth or cancer) (Kursa \& Bezrukov 2007 and references therein). However, there are very few published papers dealing with this issue in wild animals and in the case of Antarctic penguins this is only the second time that a measure of erythrocytic abnormality has been given. Moreover, there are no published studies linking the level of erythrocytic abnormalities with other biological variables. However, considering what has been found in experimental conditions in other species (e.g. Van Ngan et al. 2007), differences in this parameter very probably indicate differences in the quality of the environment.

\section{Campylobacter spp. analyses}

Our microbiological analyses include the detection of two intestinal bacteria, Campylobacter jejuni and 
Campylobacter lari. Birds are considered as natural reservoirs for Campylobacter spp. (Waldeström et al. 2002). In Antarctica, C. jejuni that exhibits the same genotype that is common in human diseases has only been isolated in macaroni penguins (Eudyptes chrysolophus Brandt) on sub-Antarctic Bird Island (Broman et al. 2000). This bacteria is absent in other Antarctic bird species while $C$. lari is widely present (see Barbosa \& Palacios 2009 for a review) which makes $C$. jejuni as a good marker for detecting potential human transmission. Bonnendahl et al. (2005) carried out a survey on pathogenic bacteria in Antarctic birds at several different places in the Antarctic Peninsula usually visited by tourists and found no evidence of the presence of $C$. jejuni, although they did detect $C$. lari. This result closely coincides with ours, as we detected only $C$. lari in both locations with no difference in their prevalence. Therefore, C. jejuni seems to be absent in Antarctica, except for the sub-Antarctic region, while $C$. lari is present in several species (Pygoscelis papua, Pygoscelis adeliae (Hombron \& Jacquinot), Phalacrocorax atriceps (King), Chionis alba Gmelin, Catharacta lonnbergi Mathews and Catharacta maccormicki Saunders) (Bonnedahl et al. 2005, Leotta et al. 2006).

\section{Stress analyses}

Baseline corticosterone levels in feathers and $\mathrm{H} / \mathrm{L}$ ratio, was higher in penguins from Devil's Point, the protected rookery, than in Hannah Point, the place with frequent human activity. Several studies have found an increase of baseline glucocorticoid levels in response to human disturbance (e.g. Wasser et al. 1997). However, other studies have found a reduction in the hormonal stress response after an induced stress situation (e.g. Walker et al. 2006, Villanueva et al. 2012) in magellanic penguins (Spheniscus magellanicus (Forster)) from tourist areas in comparison with individuals from undisturbed areas. These authors suggested that these results showed a habituation of penguins to human visitation. Although direct comparison between results from CORT levels in feathers and plasma has to be taken with caution, our results are in accordance with those obtained by Walker et al. (2006) and Villanueva et al. (2012) although their study was conducted under a stress-induced situation. Habituation has also been found elsewhere in other animals exposed to tourism, such as Galapagos marine iguanas (Amblyrhunchus cristatus (Bell)) (Romero \& Wikelski 2002) or other human disturbances in blackbirds (Turdus merula L.) (Partecke et al. 2006). It has been suggested that a reduction in stress response is developed to avoid the negative effects of repeatedly elevated glucocorticoids (Sapolsky 1992) due to chronic stress. Whether reduced stress response in gentoo penguins is beneficial or detrimental is unknown, and some probable consequences, e.g. an increase of egg or chick losses by predation, must still be tested for.

Although only marginally significant, our results also show that another measure of stress, the $\mathrm{H} / \mathrm{L}$ ratio, was also higher in the more visited colony. Increased $\mathrm{H} / \mathrm{L}$ has been reported in other bird species, among other factors, in exposure to novel social situations (Gross \& Siegel 1983) which to some extent may be similar to contact with human visitors. $\mathrm{H} / \mathrm{L}$ can be considered a measure of stress complementing corticosterone, as its sensitivity is different (Müller et al. 2011). Low $\mathrm{H} / \mathrm{L}$ seems to be provoked by some level of stress by lowering the number of heterophils and increasing the number of lymphocytes (Maxwell \& Robertson 1998) (see results above). Therefore our H/L results suggest severe stress compatible with the results of low baseline corticosterone in the more visited colony.

\section{Immunological analyses}

Immunological results show a different pattern depending on cellular (leukocyte counts) or humoral immune response (immunoglobulins). The number of lymphocytes was higher but the immunoglobulin level was lower at Hannah Point, the visited rookery, than in the protected rookery. Lowered lymphocyte counts as a consequence of increased corticosterone levels due to the immunodistribution of lymphocytes to other organs have been reported in other species (Dhabhar et al. 1995). In our case, the lower corticosterone levels from habituation detected in the visited rookery (see above) could be responsible for the higher lymphocyte count in the protected colony. An alternative explanation could be that the higher lymphocyte count was caused by a potentially higher presence of disease in the visited colony. Lymphocytes form part of the acquired immune system mainly in response to viral infection or parasite infestation (Hawkey \& Dennet 1989). Although no differences were found in bacterial infection (i.e. Campylobacter sp. see above) or ectoparasite abundance (Barbosa et al. 2011) between Hannah Point and Devil's Point, other pathogens or gastrointestinal parasites could be differentially present.

The immunoglobulin level was found to be lower in the Hannah Point penguins than those at Devil's Point. This low immunoglobulin level could be the result of immunodepression mediated by corticosterone (Saino et al. 2003). However, we have no data on corticosterone levels in plasma taken at the same time as immunoglobulin because capture and handling are assumed to induce changes which increase the corticosterone level far above the baseline considered in our study (Holberton et al. 1996). We think that low immunoglobulin level in Hannah Point is not due to higher levels of corticosterone following the patterns found in both $\mathrm{H} / \mathrm{L}$ and corticosterone in feathers. $\mathrm{H} / \mathrm{L}$ and corticosterone in feathers are measuring stress in different situations. The former expresses stress 
close to the time of capture, that is during breeding and the latter expresses stress during moulting, that is, a year before. However, the pattern found in the comparison between both localities are similar and therefore, it could be suggested that the same level of stress is affecting each locality in two different situations. Considering this, higher levels of corticosterone in plasma during breeding in Hannah Point seem to be unlikely although this remains to be studied. Our data on $\mathrm{H} / \mathrm{L}$ and corticosterone in feathers did not show any relationship with immunoglobulin in plasma supporting a lack of relationship between stress and immunology in our samples, although in the case of corticosterone in feathers can be explained by the different time of expression of the two variables (moulting in corticosterone in feathers and the time of capture in immunoglobulin in plasma). The low immunoglobulin level could also be explained by immunodistribution in which the humoral and cellular immune responses are compensated (Zuk \& Johnsen 1998). In fact, it has been hypothesized that corticosterone could be involved in this process more than in immunosupression (Braude et al. 1999).

Natural variability could also be responsible for the differences found. For instance environmental differences like differences in natural sources of trace elements or genetic differences between both populations could explain our results. However, we have chosen two gentoo penguin populations that are in close proximity in order to avoid the influence of these factors. The fact that most of the trace elements of natural origin do not show differences between both locations and that the two which show differences are linked with human activity seems to support the thesis that natural variability has not or very little influence in our results. Other factors such as genetic differences between the populations can also be excluded as genetic differences found between gentoo penguin populations are very little even at longer distances (around $330 \mathrm{~km}$ ) than between our studied colonies (Dranitsina et al. 2006).

\section{Conclusions}

Our results suggest that potential indirect effects of human impact can be observed in gentoo penguins at Hannah Point, a colony heavily visited by tourists. These penguins had higher levels of heavy metals ( $\mathrm{Pb}$ and $\mathrm{Ni}$ ) and genotoxic damage (erythrocyte malformations), lower stress indicators (baseline corticosterone in feathers and $\mathrm{H} / \mathrm{L}$ ratio), higher lymphocyte counts and lower immunoglobulin levels than in a highly protected colony such as Devil's Point located on the Byers Peninsula. Finally, this study showed both the importance of Antarctic Specially Protected Areas, such as Byers Peninsula as reference places for assessing the human impact in Antarctica, and the importance of considering penguin physiology when assessing the effects of human activity.

\section{Acknowledgements}

This study was funded by the Spanish Ministry of Science and Innovation under the POL2006-05175, POL200606635, CGL2007-60369, CTM2009-06604-E and by the European Regional Development Fund. We thank the UTM (Maritime Technology Unit, CSIC), the Spanish Polar ship Las Palmas and the Byers camp facilities for their logistic support. Permission to work in the study area and for penguin handling was granted by the Spanish Polar Committee. We would also like to thank H. Moreno for logistic support and field assistance at Byers. We especially thank C. Rochera for logistic support at the Byers Camp. This is a contribution to the International Polar Year BYERS and BIRDHEALTH projects and to the PINGUCLIM project. Deborah Fuldauer corrected the English language usage. This article was published thanks to the financial support given by the Ministerio de Ciencia e Innovación (Spain) with the grant ref. CTM2011-12973-E.

\section{References}

Afanasieva, K., Rushrovsky, S. \& Bezrukov, V. 2006. Parameters of chromosomal instability of Pygoscelis papua. Bulgaria Antarctic Research Life Sciences, 5, 9-13.

ATSDR (Agency for Toxic Substances and Disease Registry). 2005. Toxicological profile for nickel. Atlanta, GA: US Department of Health and Human Services, Public Health Service, 397 pp.

Barbosa, A. \& Palacios, M.J. 2009. Health of Antarctic birds: a review of their parasites, pathogens and diseases. Polar Biology, 32, $1095-1115$.

Barbosa, A., Merino, S., Benzal, J., Martinez, J. \& García-Fraile, S. 2007a. Geographic variation in the immunoglobulin levels in pygoscelid penguins. Polar Biology, 30, 219-225.

Barbosa, A., Merino, S., Benzal, J., Martinez, J. \& García-Fraile, S. 2007b. Population variability in heat shock proteins among three Antarctic penguin species. Polar Biology, 30, 1239-1244.

Barbosa, A., Benzal, J., Vidal, V., D’Amico, V., Coria, N., Diaz, J., Motas, M., Palacios, M.J., Cuervo, J.J., Ortiz, J. \& Chitima, L. 2011. Seabird ticks (Ixodes uriae) distribution along the Antarctic Peninsula. Polar Biology, 34, 1621-1624.

BARGAGLI, R. 2008. Environmental contamination in Antarctic ecosystems. Science of the Total Environment, 400, 212-226.

Bonnedahl, J., Broman, T., Waldenström, J., Palmgren, H., Niskanen, T. \& Olsen, B. 2005. In search of human-associated bacterial pathogens in Antarctic wildlife: report from six penguin colonies regularly visited by tourists. Ambio, 34, 430-432.

Bortolloti, G.R., Marchant, T.A., Blas, J. \& German, T. 2008. Corticosterone in feathers is a long-term, integrated measure of avian stress physiology. Functional Ecology, 22, 494-500.

Braude, S., TAng-Martinez, Z. \& Taylor, G.T. 1999. Stress, testosterone, and the immunoredistribution hypothesis. Behavioral Ecology, 10, 345-350.

Bricher, P.K., Lucieer, A. \& Woehler, W.J. 2008. Population trends of Adélie penguin (Pygoscelis adeliae) breeding colonies: a spatial analysis of the effect of snow accumulation and human activities. Polar Biology, 31, 1397-1407.

Broman, T., Bergström, S., On, S.L.V., Palmgren, H., McCafferty, D.J., Sellin, M. \& Olsen, B. 2000. Isolation and characterization of Campylobacter jejuni subsp. jejuni from macaroni penguins (Eudyptes chrysolophus) in the Subantarctic region. Applied and Environmental Microbiology, 66, 449-452. 
Carlini, A.R., Coria, N.R., Santos, M.M., Libertelli, M.M. \& Donini, G. 2007. Breeding success and population trends in Adélie penguins in areas with low and high levels of human disturbance. Polar Biology, $\mathbf{3 0}$, 917-924.

Cobley, N.D. \& ShEARS, J.R. 1999. Breeding performance of gentoo penguins (Pygoscelis papua) at a colony exposed to high levels of human disturbance. Polar Biology, 21, 355-360.

Curry, C.H., McCarthy, J.S., Darragh, H.M., Wake, R.A., Todhunter, R. \& TerRIS, J. 2002. Could tourist boots act as vectors for disease transmission in Antarctica? Journal of Travel Medicine, 9, 190-193.

DE VilLiers, M. 2008. Review of recent research into the effects of human disturbance on wildlife in the Antarctic and sub-Antarctic region. Working Paper 12, XXXI Antarctic Treaty Consultative Meeting, 2-13 June 2008, Kiev, Ukraine.

Dhabhar, F.S., Miller, A.H., McEwen, B.S. \& Spencer, R.L. 1995. Effects of stress on immune cell distribution: dynamics and hormonal mechanisms. Journal of Immunology, 154, 5511-5527.

Dranitsina, A.S., Telgeev, G.D., Maliuta, S.S. \& Bezrukov, F.V. 2006. Genetic diversity in populations of gentoo penguins (Pygoscelis papua). Tsitologiia I Genetika, 40, 57-62.

Dufva, R. \& Allander, K. 1995. Intraspecific variation in plumage coloration reflects immune response in great tit (Parus major) males. Functional Ecology, 9, 785-789.

EIsLER, R. 1998. Nickel hazards to fish, wildlife, and invertebrates: a synoptic review. Washington, DC: Geological Survey, Biological Resources Division, Biological Science Report No. 34, 86 pp.

Ellenberg, U., Setiawan, N.A., Cree, A., Houston, D.M. \& Seddon, P.J. 2007. Elevated hormonal stress response and reduced reproductive output in yellow-eye penguins exponsed to unregulated tourism. General and Comparative Endocrinology, 152, 54-63.

Fraser, W.R. \& Patterson, D.L. 1997. Human disturbance and long-term changes in Adélie penguin populations: a natural experiment at Palmer Station, Antarctic Peninsula. In Battaglia, B., Valencia, J. \& Walton, D.W.H., eds. Antarctic communities: species, structure and survival. Cambridge: Cambridge University Press, 445-452.

GIESE, M. 1996. Effects of human activity on Adélie penguin Pygoscelis adeliae breeding success. Biological Conservation, 75, 157-164.

Gochfeld, M., Belant, J.L., Shukla, T., Benson, T. \& Burger, J. 1996. Heavy metals in laughing gulls: gender, age and tissue differences. Environmental Toxicology and Chemistry, 15, 2275-2283.

Gorman, R. \& Adley, C.C. 2004. An evaluation of five preservation techniques and conventional freezing temperatures of $-20^{\circ} \mathrm{C}$ and $-85^{\circ} \mathrm{C}$ for long-term preservation of Campylobacter jejuni. Letters of Applied Microbiology, 38, 306-310.

Gross, W.B. \& SiegEL, P.B. 1983. Evaluation of the heterophil/lymphocyte ratio as a measure of stress in chicken. Avian Diseases, 27, 972-979.

HAWKEY, C.M. \& DeNNET, P.B. 1989. A color atlas of comparative veterinary haematology. Iowa City, IA: Iowa State University Press, 200 pp.

Holberton, R.L., Helmuth, B. \& Wingfield, J.C. 1996. The corticosterone stress response in gentoo and king penguins during the nonfasting period. Condor, 98, 850-854.

HoLmes, N. 2007. Comparing king, gentoo, and royal penguin responses to pedestrian visitation. Journal of Wildlife Management, 71, 2575-2582.

Holmes, N., Giese, M., Achurch, H., Robinson, S. \& Kriwoken, L.K. 2005. Behaviour and breeding success of gentoo penguins Pygoscelis papua in areas of low and high human activity. Polar Biology, 29, 399-412.

Honda, K., Yamamoto, Y., Hidaka, H. \& Tatsukawa, R. 1986. Heavy metal accumulations in Adélie penguin Pygoscelis adeliae and their variations with the reproductive success. Memoirs of National of National Institute of Polar Research, 40, 443-453.

iAATO (International Association for Antarctic Tour Operations). 2010. IAATO overview of Antarctic tourism: 2009-10 season and preliminary estimates for 2010-11 and beyond. http://image.zenn.net/ replace/client/1000037/1000115/application/msword/ATCM33_ip113.doc, accessed August 2010.
Janes, M.E., Bower, R.K. \& Anthony, N.B. 1994. The leukocyte response of Japanese quail to Rous sarcoma virus-induced tumors. Avian Diseases, 38, 610-615.

Jerez, S., Motas, M., Cánovas, R.A., Talavera, J., Almela, R.M. \& BAYÓN, A. 2010. Accumulation and tissue distribution of heavy metals and essential elements in loggerhead turtles (Caretta caretta) from Spanish Mediterranean coastline of Murcia. Chemosphere, 78, 256-264.

Jerez, S., Motas, M., Palacios, M.J., Valera, F., Cuervo, J.J. \& Barbosa, A. 2011. Concentrations on trade elements in feathers of three Antarctic penguins: geographical and interspecific differences. Environmental Pollution, 159, 2412-2419.

Kursa, M. \& Bezrukov, V. 2008. Health status in an Antarctic top predator: micronuclei frequency and white blood cells differentials in the south polar skua (Catharacta maccormicki). Polarforschung, 77, $1-5$.

Leotta, G., Vigo, G. \& Giacoboni, G. 2006. Isolation of Campylobacter lari from seabirds in Hope Bay, Antarctica. Polish Polar Research, 27, 303-308.

Lynch, H.J., Fagan, W.F. \& Naveen, R. 2010. Population trends and reproductive success at a frequently visited penguin colony on the western Antarctic Peninsula. Polar Biology, 33, 493-503.

Martinez, J., Tomas, G., Merino, S., Arriero, E. \& Moreno, J. 2003. Detection of serum immunoglobulins in wild birds by direct ELISA: a methodological study to validate the technique in different species using antichicken antibodies. Functional Ecology, 17, 700-706.

Maxwell, M.H. \& Robertson, G.W. 1998. The avian heterophil leucocyte: a review. World Poultry Science Journal, 54, 155-178.

Metcheva, R., Yurukova, L., Teodorova, S. \& Nikolova, E. 2006. The penguin feathers as bioindicator of Antarctica environmental state. Science of the Total Environment, 362, 259-265.

Moreno, J., de Leon, A., Fargallo, J.A. \& Moreno, E. 1998. Breeding time, health and immune response in the chinstrap penguin Pygoscelis antarctica. Oecologia, 115, 312-319.

Müller, C., Jenni-Eiermann, S. \& Jenni, L. 2011. Heterophils/lymphocytesratio and circulating corticosterone do not indicate the same stress imposed on Eurasian kestrel nestlings. Functional Ecology, 25, 566-576.

Nimon, A.J., Schroter, R.C. \& Stonehouse, B. 1995. Heart rate of disturbed penguins. Nature, 374, 415.

OtLey, H.M. 2005. Nature-based tourism: experiences at Volunteer Point penguin colony in the Falkland Islands. Marine Ornithology, 33, $181-187$.

Partecke, J., Schwabl, I. \& Gwinner, E. 2006. Stress and the city: urbanization and its effects on the stress physiology in European blackbirds. Ecology, 87, 1945-1952.

Romero, L.M. \& WiKelsKi, M. 2002. Corticosterone levels predict survival probabilities of Galapagos marine iguanas during El Niño events. Proceedings of the National Academy of Sciences of the United States of America, 98, 7366-7370.

Saino, N., Suffritti, C., Martinelli, R., Rubolini, D. \& Moller, A.P. 2003. Immune response covaries with corticosterone plasma levels under experimentally stressful conditions in nestling barn swallows (Hirundo rustica). Behavioral Ecology, 14, 318-325.

SAPOLSKY, R.M. 1992. Neuroendocrinology of the stress response. In Becker, J.B., Breedlove, S.M. \& Crews, D., eds. Behavioural endocrinology. Cambridge, MA: MIT Press, 287-324.

Schmid, W. 1975. Micronucleus test. Mutation Research, 31, 9-15.

Scheuhammer, A.M. 1987. The chronic toxicity of aluminium, cadmium, mercury and lead in birds: a review. Environmental Pollution, 46, 263-295.

Smichowski, P., Vodopivez, C., Muñoz-Olivas, R. \& Gutierrez, A.M. 2006. Monitoring trace elements in selected organs of Antarctic penguin (Pygoscelis adeliae) by plasma-based techniques. Microchemical Journal, 82, 1-7. 
Snoeiss, T., Daume, T., Pinxten, R., Vandesande, R. \& Eens, M. 2004. Heavy metal exposure affects the humoral immune response in a free-living small songbird, the great tit (Parus major). Archive Environmental Contamination and Toxicology, 46, 399-404.

Steele, T.W. \& McDermott, S.N. 1984. The use of membrane filters applied directly to the surface of agar plates for the isolation of $C$. jejuni from faeces. Pathology, 16, 263-265.

Stoncius, D. \& LazutKa, J.R. 2003. Spontaneous and benzo[a]pyreneinduced micronuclei in the embryos of the black-headed gull (Larus ridibundus L.). Mutation Research-Genetic Toxicology and Environmental Mutagenesis, 538, 31-39.

Tin, T., Fleming, Z.L., Hughes, K.A., Ainley, D.G., Convey, P., Moreno, C.A., Pfeiffer, S., Scott, J. \& Snape, I. 2009. Impacts of local human activities on the Antarctic environment. Antarctic Science, 21, 3-33.

Trathan, P.N., Forcada, J., Atkinson, R., Downie, R.H. \& Shears, J.R. 2008. Population assessments of gentoo penguins (Pygoscelis papua) breeding at an important Antarctic tourist site, Goudier Island, Port Lockroy, Palmer Archipelago, Antarctica. Biological Conservation, 141, 3019-3028.
Van Ngan, P.V., Gomes, V., Passos, M.J.A.C.R., Ussami, K.A., Campos, D.Y.F., Da Silva, A.J. \& Pereira, B.A. 2007. Biomonitoring of the genotoxic potential (micronucleus and erythrocyte nuclear abnormalities assay) of the Admiralty Bay water surroundings the Brazilian Antarctic Research Station "Comandante Ferraz", King George Island. Polar Biology, 30, 209-217.

Villanueva, C., Walker, B.G. \& Bertelotti, M. 2012. A matter of history: effects of tourist on physiology, behaviour and breeding parameters in Magellanic penguins (Spheniscus magellanicus) at two colonies in Argentina. Journal of Ornithology, 153, 219-228.

Waldeström, J., Broman, T., Carlsson, I., Hasselquist, D., Achterberg, R.P., WagenaAR, J.A. \& Olsen, B. 2002. Prevalence of Campylobacter jejuni, Campylobacter lari and Campylobacter coli in different ecological guilds and taxa for migrating birds. Applied and Environmental Microbiology, 68, 5911-5917.

Walker, B.G., Boersma, P.D. \& Wingfield, J.C. 2006. Habituation of adult magellanic penguins to human visitation as expressed through behavior and corticosterone secretion. Conservation Biology, 20, 146-154.

ZuK, M. \& Johnsen, T.S. 1998. Seasonal changes in the relationship between ornamentation and immune response in red jungle fowl. Proceedings of the Royal Society of London, B265, 1631-1635. 